\title{
EVOLUTION, DISPERSAL AND HABITAT PREFERENCE OF DEEP-SEA TRACE FOSSILS
}

CRIMES, T. Peter, Dept. of Earth Sciences, University, Brownlow Street, Liverpool L69 3BX, U.K.

Cambrian deep-sea sediments have yielded few trace fossils. The first moderately diverse suite is found in an Arenig flysch sequence in Eire. There followed a gradual increase in diversity and abundance of trace fossils in deep-sea niches in the Palaeozoic and early Mesozoic. A major burst of behaviourial evolution appears to have taken place during the Cretaceous and, from then through the Tertiary, high levels of trace fossil abundance and diversity were maintained. This is confirmed by recent work on Miocene deep-sea sequences and from a superbly preserved, diverse, ichnofauna recently discovered in strata of Oligocene and Miocene age in the Makran Range of Iran.

In the past, it has been inferred that there was a gradual improvement in behavioral programming in deep-sea traces, with a trend towards economy of effort and perfection. However, Lower Palaeozoic deep water traces show careful, complex, behavioral programming which was to change little through the rest of the Phanerozoic.

Within the deep-sea, there are, however, significant variations in the ichnospectrum in different niches. For example, the inner parts of seep-sea sand fans, particularly the channelled areas, have a mixture of "deep" and "shallow" water traces, whereas the outer fan normally has only deep water forms. 